\title{
NEPHROCALCINOSIS INFANTUM
}

\author{
BY \\ ROBERT A. SHANKS and A. M. MACDONALD \\ From The Royal Hospital for Sick Children, Yorkhill, Glasgow
}

(RECEIVED FOR PUBLICATION SEPTEMBER 10, 1958)

Since Lightwood's description in 1935 of six cases of renal calcinosis encountered in a series of 850 autopsies this condition has attracted widespread attention and has been recorded in association with many different diseases including renal acidosis, idiopathic hypercalcaemia, hypophosphatasia, hyperoxalaemia and sarcoidosis. In addition to the cases in which the clinical diagnosis would suggest such a lesion, nephrocalcinosis has been found at autopsy in several infants dying in this hospital of apparently unrelated diseases. The purpose of this paper is to describe the results of a survey of all cases of nephrocalcinosis encountered at autopsy in the Royal Hospital for Sick Children, Glasgow, during the past three decades.

Until the middle of 1949 , kidneys were examined histologically only when there was some indication to do so; figures for the incidence of nephrocalcinosis before this date will therefore be incomplete but may perhaps be presumed to include those macroscopically obvious. After this period the kidneys were examined in every autopsy and in most cases re-examired in order to ensure that none was missed. In the period under review (1928-57) there were 84 cases in all, of which 60 occurred during the decade 1949-57. Excluding the first five months of 1949 the figures for this latter decade can be taken as representing the true incidence of this lesion in children coming to autopsy (Table 1).

TABLE 1

INCIDENCE OF NEPHROCALCINOSIS AT AUTOPSY

\begin{tabular}{cc|c|c|c}
\hline Year & & $\begin{array}{c}\text { No. of } \\
\text { Autopsies }\end{array}$ & $\begin{array}{c}\text { Kidneys } \\
\text { Examined }\end{array}$ & No. of Cases \\
\cline { 3 - 4 } $1928-37$ & $\cdots$ & 2,673 & 187 & 9 \\
$1938-47$ & $\cdots$ & 2,672 & 251 & 15 \\
$1948-57$ & $\cdots$ & 1,751 & 1,475 & 60 \\
\hline
\end{tabular}

The detailed histology of the lesion of nephrocalcinosis has already been described by Rhaney and Mitchell (1956) who had access to some of our material. On closer examination of our series, however, it became evident that what appeared to be various stages in the production of the fully developed picture could be identified in the same tissue including an early lesion in which deposition of calcium had not yet occurred. Thereafter on a further survey of the histological sections in this series a number of cases were found in which this early lesion occurred alone. Such cases have been included in our series in the conviction that they are indications of the same pathological process and the apparent illogicality of including lesions without demonstrable calcium under the term nephrocalcinosis was thought preferable to deviating from a term now firmly established in the medical literature.

For the purpose of description we have classified the histological appearances according to the following criteria.

Type I. Scanty Precalcinotic Lesions. These are small and obviously early lesions characterized by the distension of a single tubule which sometimes contains a hyaline cast. The epithelium shows minor damage such as blurring of the cell outline, pyknosis of the nuclei and loss of definition of the basement membrane which is replaced by acellular granular debris and occasionally accompanied by a giant cell (Fig. 1).

Type U. Abundant Precalcinotic Lesions. These lesions are larger than those of Type I and involve several adjacent tubules (Fig. 2). The number of tubules involved varies from lesion to lesion while the degree of distortion may be such as to make them barely recognizable. In some a giant cell may be seen but in none can calcium be demonstrated. The connective tissue surrounding the lesion is condensed; later there is an increase in fibrous tissue which eventually obliterates the lesion to become a fibrous node (Fig. 3). The lesions are irregularly distributed along the affected tubules which may be obstructed at several levels (Fig. 4). Depending upon the chance cut of the histological section examined, a cystic or granulomatous appearance may then appear in the same field. 


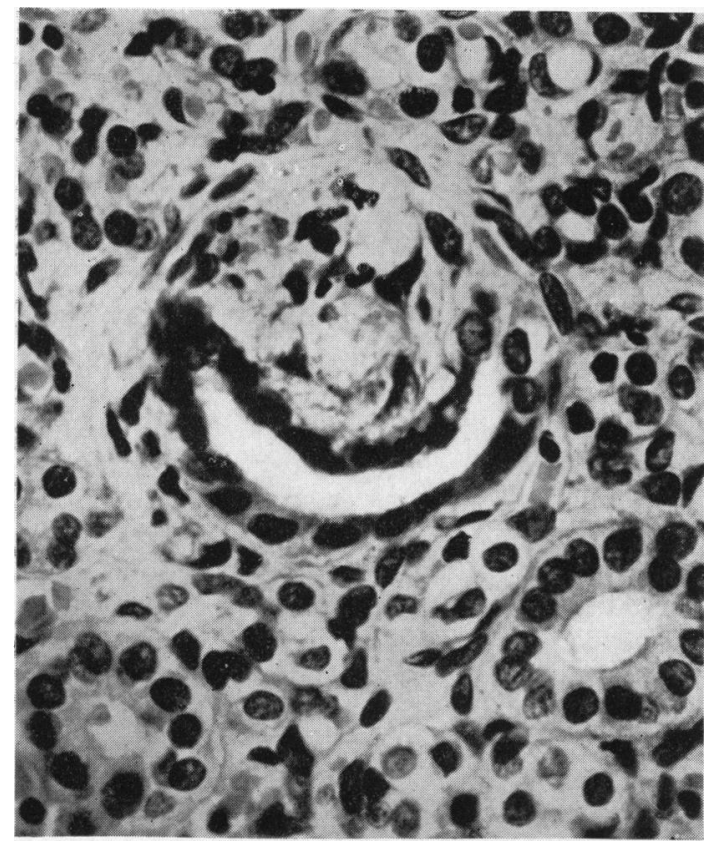

FIG. 1. Type I. Scanty precalcinotic lesion. A single tubule distended and showing nuclear pyknosis and early deposition of acellular granular debris adjacent to it. H. and E. $\times 580$.

Type III. Renal Medullary Calcinosis. These lesions are almost completely confined to the renal medulla and some but not all show demonstrable calcium. For convenience three sub-types are described: (a) infrequent lesions found near the cortex differing from Type $I$ in the presence of deposited calcium. (b) Abundant lesions of the renal medulla with occasionally a few minimal cortical lesions as well; the renal damage is as extensive as in Type II from which it is distinguished by a heavy deposit of stainable calcium (Fig. 5): this is always recognizable to the naked eye. These, too, may become fibrotic (Fig. 6). The characteristic position near the cortex suggests involvement of Henle's loop. All in all this group may be taken as the picture of renal medullary calcinosis at its height, a picture which has already been amply described (Rhaney and Mitchell, 1956). (c) These are scanty lesions differing from Type IIIa in their position which is in the papilla rather than the juxta-cortical zone. They have been found in association with pyelonephritis and pelvic calculi and are probably unrelated to the other types described. They account for only two of the total of 84 cases seen in the period under review.

Type IV. Renal Medullary and Cortical Calcinosis. The only histological criterion for this group is the presence of calcinotic lesions not only in the renal medulla but to a considerable extent in the cortex also; the glomeruli, however, are not affected. The medullary lesion is usually more extensive. The example illustrated is a severe lesion (Fig. 7).

Type V. Renal Cortical Calcinosis. These lesions are nearly entirely confined to the cortex and any medullary lesions present are very scanty and small.

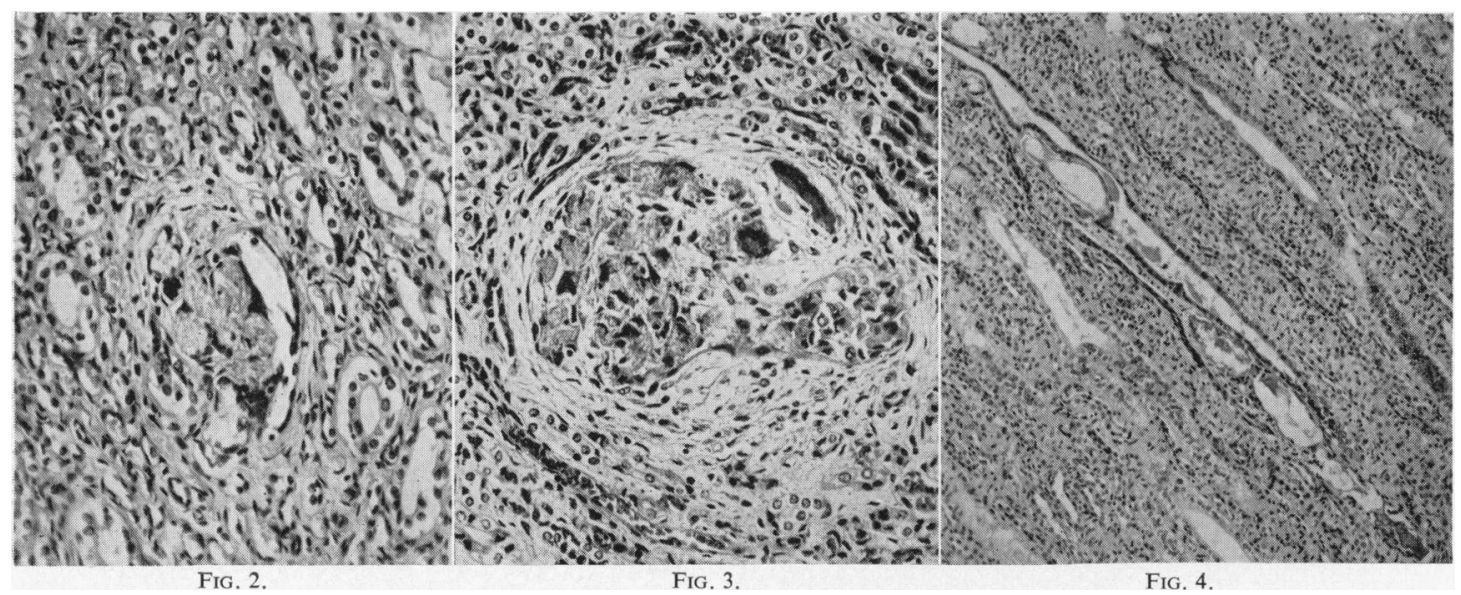

Fig. 2. Type II. Abundant precalcinotic lesions. Several adjacent tubules involved in a granulomatous mass. Early 'giant cell' formation is shown. Many such lesions are found. H. and E. $\times 170$.

FIG. 3. Type II. Abundant precalcinotic lesions. Evidence of early fibrosis around the lesion. H. and E. $\times 170$.

FIG. 4.-Type II. Precalcinotic lesion. Longitudinal section of tubules to show obstruction at different levels and pressure collapse of adjacent tubules. The cystic appearance is considered to be artefact. In life debris lay in the space which is outside the tubule in the site of the basement membrane. H. and E. $\times 75$. 




FIG. 5.-Type IIIb. Medullary calcinosis. Mass of calcium replacing group of adjacent tubules in varying stages of distension and obliteration. H. and E. $\times 190$.

They have been found only in the first two decades under review.

Type VI. Unclassified. Two lesions have been included merely because the presence of stainable calcium brings them into the category of nephrocalcinosis; they are clearly not related to any of the foregoing, one being the end result of a venous thrombosis, the other calcification of a renal vein in a child with extensive pyelonephritis.

\section{Results}

The general incidence of these lesions at autopsy is seen in Table 1. The incidence of the several types is shown in Table 2. For the reasons

TABLE 2

INCIDENCE OF RENAL LESION ACCORDING TO TYPE

\begin{tabular}{r|r|r|r|r|r|r|r|r}
\hline & \multicolumn{8}{|c}{ Type } \\
Year & I & II & IIIa & IIIb & IIIc & IV & V & VI \\
\hline $1928-37$ & 1 & 0 & 1 & 3 & 1 & 0 & 3 & 0 \\
$1938-47$ & 2 & 1 & 4 & 3 & 0 & 2 & 2 & 1 \\
$1948-57$ & 12 & 13 & 4 & 20 & 3 & 7 & 0 & 1 \\
\hline
\end{tabular}

mentioned above, only the figures for the most recent decade can be regarded as comprehensive. Nevertheless, if we accept the suggestion that severe medullary calcinosis is unlikely to be missed at autopsy, we can conclude that for Type IIIb at least, the earlier figures, too, provide an index of its occurrence and a suggestion that the greatly

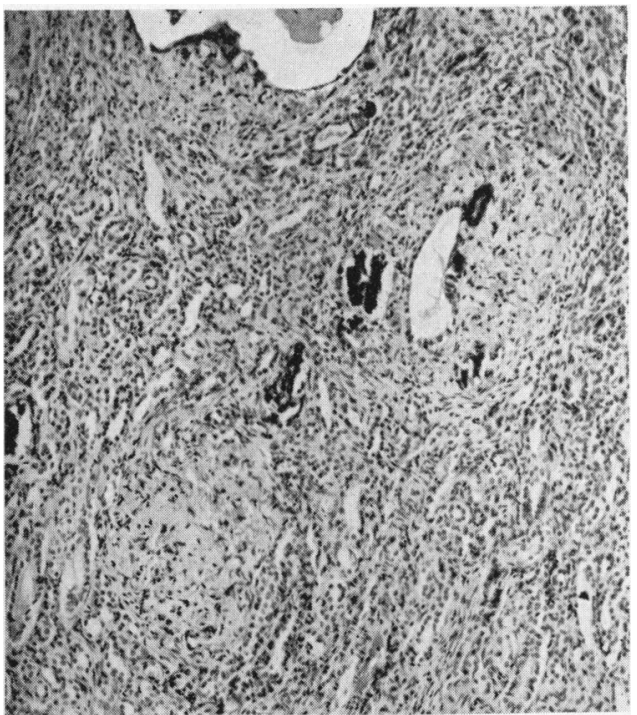

FIG. 6.-Type IIIb. Medullary calcinosis. Fibrous nodes, some containing calcium. The healing lesion.

H. and E. $\times 85$.

increased numbers of cases of nephrocalcinosis found in the period 1948-57 reflect a true increase in its incidence. Nevertheless, the figures for the first two decades are so small that detailed con-



FIG. 7.-Type IV. Renal medullary and cortical calcinosis. Calcium deposition in the tubules in the cortex. Glomeruli not affected. H. and E. $\times 230$. 
sideration will be confined to the figures for 1948-57.

The age incidence is shown in Table 3 and it is clear that nephrocalcinosis is primarily a disorder of infancy and rarely occurs over the age of 2 years. Of the 47 infants in the last decade there were 10 in the first three months, 19 in the second, 10 in the third and eight in the last. Thus almost half the total 60 cases were under 6 months of age at death and it follows that the condition has its origin during this period in an even larger proportion.

TABLE 3

AGE INCIDENCE

\begin{tabular}{|c|c|c|c|c|}
\hline \multirow[b]{2}{*}{ Year } & \multicolumn{4}{|c|}{ Age in years } \\
\hline & $0-1$ & $1-2$ & $2-3$ & Over 3 \\
\hline $\begin{array}{ll}1928-37 & \ldots \\
1938-47 & \ldots \\
1948-57 & \ldots\end{array}$ & $\begin{array}{r}3 \\
9 \\
47\end{array}$ & $\begin{array}{r}1 \\
1 \\
10\end{array}$ & $\begin{array}{l}0 \\
2 \\
0\end{array}$ & $\begin{array}{l}5 \\
3 \\
3\end{array}$ \\
\hline
\end{tabular}

Clinical Diagnosis. A retrospective clinical appreciation of each case was undertaken in order to determine as far as possible the associated clinical condition and symptomatology which might be related to the kidney lesion. It became abundantly clear that only a few of the children with postmortem nephrocalcinosis were recognized in life to be suffering from one of the known causes of this lesion. Of the 60 cases only 12 belonged to what we may call the 'renal acidosis' group. Four were diagnosed as hyperchloraemic renal acidosis, seven as idiopathic hypercalcaemia while an additional child had both. Table 4 shows the distribution of clinical and pathological diagnoses under fairly general headings. It will be appreciated that as several children had more than one pathological condition, the total number of diagnoses exceeds the number of cases.

Symptomatology. A detailed analysis of the symptoms and in particular of such symptoms as vomiting and constipation which are frequently associated with the clinical syndrome of idiopathic hypercalcaemia was unprofitable. Vomiting in fact occurred in 40 cases and constipation in 21 but in most cases this could easily be attributed to the associated disease from which the child died.

Vitamin D. Information regarding vitamin D intake was not complete in all records. In 52 there was a history of prolonged administration of fortified milk and/or vitamin $D$ supplements. In two infants there was no history of administration of vitamin $\mathrm{D}$ in significant amounts. One who died of fibrocystic disease of the pancreas had been given cod liver oil for one week only and received milk fortified with vitamin $\mathrm{D}_{2}$ only during her fortnight's stay in hospital: the lesion found at autopsy was Type II. The other who died of hyperchloraemic renal acidosis and enteritis had been given fortified milk for three weeks and cod liver oil in moderate doses for two weeks.

\section{Discussion}

It is apparent that a wide variety of pathological conditions, in themselves sufficient to cause death, have been found in association with the lesion of nephrocalcinosis. Indeed the distribution of diagnoses in our series is merely one that would be expected in any selection of autopsies of this age group. The first and most obvious explanation for these findings is that nephrocalcinosis is a casual autopsy finding, seldom related to the cause of death. The virtual absence of the condition in children over the age of 2 years likewise suggests that not only is it usually not lethal, it normally proceeds to complete resolution. Clearly no group of lesions which may be produced by such widely different causes as hypophosphatasia and hyperoxaluria can be regarded as homogeneous. Nevertheless, the implications are that most of them belong to a benign disorder of infancy without severe symptoms and with an excellent prognosis.

TABLE 4

DIAGNOSES OF 60 CASES OF NEPHROCALCINOSIS SEEN DURING 1948-57

\begin{tabular}{|c|c|c|c|c|c|c|c|c|c|c|}
\hline & & & & & & $\begin{array}{c}\text { Congenital } \\
\text { Abnormality }\end{array}$ & Infection & Miscellaneous & Total & $\begin{array}{l}\text { Percentage } \\
\text { Total Cases }\end{array}$ \\
\hline $\begin{array}{l}\text { System: } \\
\text { Alimentary } \\
\text { Respiratory } \\
\text { Cardiovascular } \\
\text { Central nervous } \\
\text { Genito-urinary (ex } \\
\text { Miscellaneous Conditic } \\
\text { Renal acidosis } \\
\text { Hypercalcaemia } \\
\text { Hypophosphatasia } \\
\text { Others ... }\end{array}$ & $\begin{array}{l} \\
\ldots \\
\cdots \\
\cdots \\
\text { exci. ne } \\
\text { ions: } \\
\cdots \\
\cdots \\
a\end{array}$ & $\begin{array}{l}\ldots \\
\ldots \\
\ldots \\
\text { ephrocal } \\
\ldots \\
\ldots \\
\ldots\end{array}$ & $\begin{array}{l}\ldots \\
\ldots \\
0 \\
\text { lcinosis) } \\
\ldots \\
\ldots \\
\ldots\end{array}$ & 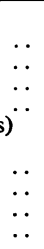 & $\begin{array}{c}. . \\
. \\
. \\
. \\
. . \\
. \\
.\end{array}$ & $\begin{array}{r}5 \\
-\frac{5}{6} \\
10 \\
1\end{array}$ & $\begin{array}{c}14 \\
16 \\
4 \\
1\end{array}$ & $\begin{array}{l}\frac{8}{-} \\
4 \\
1 \\
5 \\
8 \\
1 \\
6\end{array}$ & $\begin{array}{r}27 \\
16 \\
6 \\
18 \\
3 \\
20\end{array}$ & $\begin{array}{r}45 \\
26 \\
10 \\
30 \\
5 \\
33\end{array}$ \\
\hline
\end{tabular}


This brings it into line with the condition of idiopathic hypercalcaemia of infancy which is known to be relatively benign and known also to produce renal medullary calcinosis in those few that have come to autopsy. In this hospital there have been 40 cases of idiopathic hypercalcaemia recognized during the past seven years and of these four died (McBean, 1958). Three came to autopsy and renal medullary calcinosis was found in all.

A simple theory which would appear to satisfy the facts at our disposal is that symptomless hypercalcaemia is a more widespread condition than has been appreciated and that renal lesions thereby produced are only detected when the child happens to die of some other condition. When hypercalcaemia is more severe or prolonged, symptoms are produced which lead to a clinical diagnosis. During the second year of life the lesions presumably resolve leaving no scar. It is tempting to regard this as yet another pointer to the association between idiopathic hypercalcaemia, nephrocalcinosis and vitamin $\mathbf{D}$ for it is at this age that children usually cease to be given milk and cereals which are fortified with synthetic vitamin $D$.

\section{Summary}

Eighty-four cases of nephrocalcinosis infantum have been encountered during the thirty-year period 1928-57 and of these 60 occurred in the last decade. It is thought that this indicates a true increase in the incidence. Most cases $(70 \%)$ were found in the first year of life.

An early lesion in which calcium has not yet been deposited can be recognized.

Nephrocalcinosis infantum appears to be a benign lesion and unrelated to the cause of death. It is concluded that the lesion resolves spontaneously during the second year of life and is probably related to symptomless hypercalcaemia however caused.

We are grateful to our senior colleagues for permission to report cases under their care.

\section{REFERENCES}

Lightwood, R. (1935). Arch. Dis. Childh., 10, 205

Rhaney, K. and Mitchell, R. G. (1956). Lancet, 1, 1028.

McBean, M. S. (1958). Personal communication. 